\title{
Knowledge Management from Senior Users of Online Health Information Point of View
}

\author{
Tobba Therkildsen Sudmann, Eva Haukeland Fredriksen, Ingebjørg Træland Børsheim and \\ Ilona Heldal \\ Western Norway University of Applied Sciences, Bergen, Norway \\ tsu@hvl.no
}

ORCID Tobba Therkildsen Sudmann https://orcid.org/0000-0002-7482-9984

ORCID Eva Haukeland Fredriksen https://orcid.org/0000-0001-5609-8308

ORCID Ingebjørg Træland Børsheim https://orcid.org/0000-0003-4706-7790

ORCID Ilona Heldal https://orcid.org/0000-0003-1149-8820

\begin{abstract}
In today's society, all citizens who need digital information to manage their everyday life must be able to access it and trust it. They should have enough knowledge to use information and communication technologies (ICTs) and online health information $(\mathrm{OHI})$ in an intended and purposeful way. The broader aim of this paper is to present and discuss health knowledge management (KM) from senior users of the online health information point of view. The theoretical point of departure is based on an understanding of health, knowledge and the Internet as social practices. This paper investigates eHealth literacy (eHL) and KM in health amongst seniors aged 65-90. It presents a case study on how they access, apprais, share and apply $\mathrm{OHI}$ in comparison to the way they use face-to-face health-encounters. Data comes from 17 open-ended interviews. E-HL and KM concepts are used to analyse and describe online behaviour and knowledge management in health as an interplay between individual and social factors. The results show how participants engage in self- and co-management of their own or others' health and illustrate how they get or receive help to understand OHI. By examining how they use ICT and do (not) trust $\mathrm{OHI}$ regarding "serious cases," this paper provides critical insight into ways seniors acquire information and how they appraise, understand or trust in it. Their information-seeking activities are performed mainly in private settings, seldom with professionals. They have lower levels of trust in their own, individual appraisal skills, compared to collective searches and discussions. Norwegian seniors are cool and pragmatic, and emphatic on the "when needs must, see your GP!". By examining differences in ICT use, knowledge acquisition and support given or received, the results pinpoint how providers must affirm seniors' ICT use and individual and collective online health behaviour as assets for healthy ageing. A potential barrier for citizens' use of $\mathrm{OHI}$ and health technology is the built-in understanding of health as an individual capacity and ICT use as an individual activity, compared to a contemporary understanding of health and the Internet as social practices and collective resources. Designers of health technologies and $\mathrm{OHI}$ should critically consider built-in understandings of content and users to enhance accessibility and value for citizens of all ages.
\end{abstract}

Keywords: healthy ageing, knowledge management, e-health literacy, online health information, knowledge sharing, social practice

\section{Introduction}

The global trend towards longevity is followed by efforts towards healthy ageing and ageing in place, i.e. at home (Stephens, 2017; Wiles et al., 2011). Digitisation and health technology are suggested as appropriate response to expected societal changes (Wagner, Hassanein and Head, 2010). Key drivers towards digitalised societies, e.g. the rapid development of health technology and the political and structural processes towards self-management of health, exercises a pressure on citizens to find, critically appraise and use digitized knowledge and health technology individually or collectively. This paper investigates how a group of Norwegian seniors aged 65-90 managed their own and others health through online activities, and how they create, share and use online health information.

The aim of this paper is to present and discuss health knowledge management (KM) from senior users' of online health information point of view. The theoretical point of departure for this paper is based on an understanding of health, knowledge and the Internet as social practices. Accordingly, the concepts e-health literacy and KM need to be elaborated and discussed in relation to healthy ageing.

The structure of the paper comprises the following sections. The introductory section presents the setting for health KM and online health information; healthy ageing, e-health literacy and KM in a general health context. The second section presents the research methodology, the qualitative interview design and participants, and analytical strategies. In the third section, the empirical material is presented and illustrated with quotes from 
the participants. The last two sections comprise discussions and offer conclusions and suggestions for health technology developers, health care workers, and further research.

\subsection{Healthy ageing}

Life expectancy is increasing globally (World Health Organization, 2017b). The ability to make healthy choices build on a complex set of skills and competencies, e.g. knowledge about your own body, nutrition, activity, symptoms or diseases, and how healthcare services are organised and accessed (Levesque, Harris and Russell, 2013b). Healthy ageing and longevity are related to how individuals and groups choose, adapt and co-/selfmanage in the face of social, physical and emotional challenges (Huber et al., 2011). The combination of longevity and digitization of health services have raised concerns about evolving digital divides (World Health Organization, 2016; Friemel, 2016; Hall et al., 2015; Rhoades et al., 2017) and digital exclusion in later life (Matthews, Nazroo and Marshall, 2018; Tennant et al., 2015; Silver, 2015; Kickbusch, 2001). Digital proficiency in online health information activities demands a minimum of socio-material resources (e.g. ICT equipment, electricity, Internet access), bodily capacities (e.g. cognition, hearing, sight, dexterity) and knowledge and executive functioning (understanding, analysing, decision-making) (Weck, Helander and Meristö, 2020). In many cases, especially in these Covid19 times, not mastering digital information might lead to social isolation and mental health problems (Gerst-Emerson and Jayawardhana, 2015; Armitage and Nellums, 2020). Citizens, as patients, are expected to find and engage with online health services, e.g. booking appointments, ordering prescriptions, or sharing electronic health records (EHRs).

Healthy ageing presupposes possibilities to take part in physical and social activities, and to be able to exercise agency and citizenship rights and duties. Rowe and Kahn introduced the concept of healthy ageing to denote the common denominators they found to be positive for longevity, i.e. minimizing the risk of disease and disability, maintaining physical and cognitive well being and continuing the engagement in social life (Rowe and Kahn, 1997). Several authors have criticised their concept for being too individualistic and biased towards the western ideology of well-being and individual happiness. Their first attempt at defining successful ageing were also critiqued for offering a top down definition of longevity and well-being, ignoring individual and contextual factors (Bowling and Dieppe, 2005). Row and Kahn (2015) have complied with some of this critique in their second version of successful ageing. They suggest that their model is better used as a resource, not as a receipt, influenced by an overall perspective considering e.g. cultural, societal factors, institutional structures, life course, and various biometrics. Stephens (2017) has suggested that the focus should be on capabilities, which focuses on possibilities for learning and growth. Our study illustrates how being able and willing to engage in digital KM as part of healthy and active ageing is all about capabilities - own, others or societal.

\subsection{E-Health literacy}

In an ageing world, healthy ageing and longevity are related to how individuals and groups use available healthrelated resources to make healthy decisions, to adapt, and co-manage or self-manage in the face of social, physical, and emotional challenges (Huber et al., 2011). All citizens should have the opportunity to make healthy choices and be knowledgeable about their own body, nutrition, physical activity, symptoms, or diseases and know how health care services are organized and accessed (Levesque, Harris and Russell, 2013a). However, todays seniors' knowledge about health or health care systems is a composite of what they learned through their lifetime, which may be outdated or no longer valid due to re-organisation of the healthcare systems. Acquisition and appreciation of current and valid health-related skills and knowledge presupposes lifelong learning and particular skills and competencies. Contemporary health resources are digitised, and seniors are expected to master health related technology, i.e. be e-health literate.

Knowledge acquisition in a digitised society is related to digital proficiency in online health information activities, access to digital technologies and the Internet, bodily capacities (e.g. cognition, hearing, sight, dexterity), and knowledge and functioning (understanding, analysing, decision-making). This paper builds on a study of how a selected group of Norwegian seniors between 65-90 years use ICT to access, appraise and apply online health information $(\mathrm{OHI})$, and how they evaluate this information compared to face-to-face health-encounters.

The combination of longevity and digitisation of health services has raised concerns about evolving digital divides (World Health Organization, 2017a; Friemel, 2016; Hall et al., 2015; Rhoades et al., 2017) and digital exclusion in later life (MatthewsNazroo and Marshall, 2019; Tennant et al., 2015; Kickbusch, 2001; Silver, 2015). Responding to this concern can be challenging: "Despite the significance of this phenomenon, the information systems (IS) literature lacks a comprehensive consideration and explanation of technology acceptance in general 
and, more specifically, Internet adoption by the elderly." (Niehaves and Plattfaut, 2014). There are many influencing factors based on societal, individual, or technological differences. This divide may manifest differently in different countries (Nishijimalvanauskas and Sarti, 2017) based on individual characteristics (Van Deursen and Helsper, 2015) or, for example, the national features of the used OHI system (Wang et al., 2008). Since $\mathrm{OHI}$ is beginning to be not only a right but also an opportunity to contact healthcare services, exploring attitudes towards it is necessary both, for democracy, but also to achieve accessible healthcare for all. Citizens in western countries, as patients, are expected to use ICT and to find and engage with online health services, e.g. booking appointments, ordering prescriptions, or sharing electronic health records (EHRs). Several authors are worried about using EHRs whitout anchoring it with different professionals and patients (Wiljer et al., 2008; Zurita and Nøhr, 2004; Goroll, 2017; BossenChen and Pine, 2019). As an example, Hemsley et al. (2018) argue that electronic personal health records (e-PHR) exert new demands on patients and health care service providers e.g. cognitive capabilities, education, ICT literacy, and willingness to share health information. They warn that high literacy demands on e-PHR is a potential threat to health outcomes.

Contemporary framing of e-health literacy (eHL) departs from Nutbeam's (2008) seminal research, which showed a connection between literacy skills and health status, i.e. health outcomes. His Lily model, with 6 petals, refers to different literacies: traditional (reading, writing, calculating), computer, media, science, information, and health and health services. The Lily model has been criticised for ignoring socio-economic factors, context and individual and group-based differences. Several scholars have attempted to amend or create a new model of eHL, making a plethora of definitions available (Gilstad, 2014; Bautista, 2015; Nørgaard et al., 2015; Griebel et al., 2018).

Gilstad (2014) offers an amendment to Nutbeam's Lily model (see Figure 1.), and a new definition of eHL: eHealth literacy is the ability to identify and define a health problem, to communicate, seek, understand, appraise and apply eHealth information and welfare technologies in the cultural, social and situational frame and to use the knowledge critically in order to solve the health problem. (Gilstad, 2014).
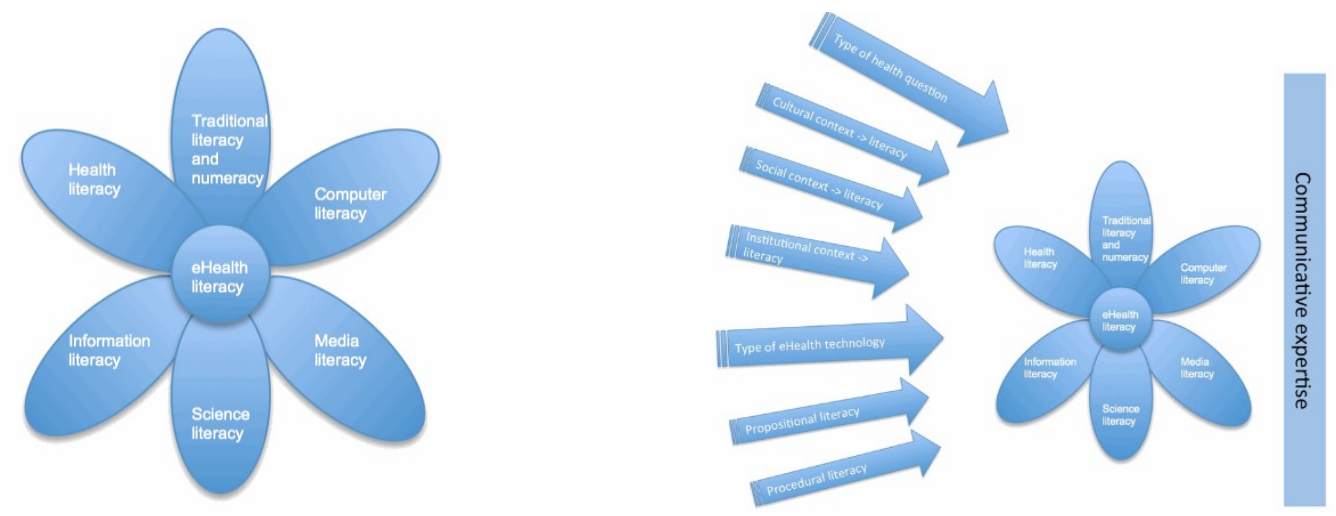

Figure 1: The left side shows Nutbeam's Lily model and the right side Gilstad's amendment with contextual factors influencing eHL and the communicative expertice (from Gilstad (2014). Permission to reprint the figue is obtained from the rightsholder

Nørgaard et al. (Nørgaard et al., 2015) propose an eHL-framework, which focuses on individual's and population's capacity to understand, use and take benefit from technology to promote and maintain their own health (see Figure 2.). The interaction between an individual's ability to process information and engage in their own, personal health and system requirements (accessible and suitable systems) gives the individual a sense of safety and control, and motivation to engage in digital services. Their framework is composed of seven domains (Nørgaard et al., 2015):

1. Ability to process information

2. Engagement in own health

3. Ability to engage actively with digital services

4. Feeling safe and in control

5. Motivation to engage with digital services

6. Having access to systems that work

7. Digital services that suit individual needs. 


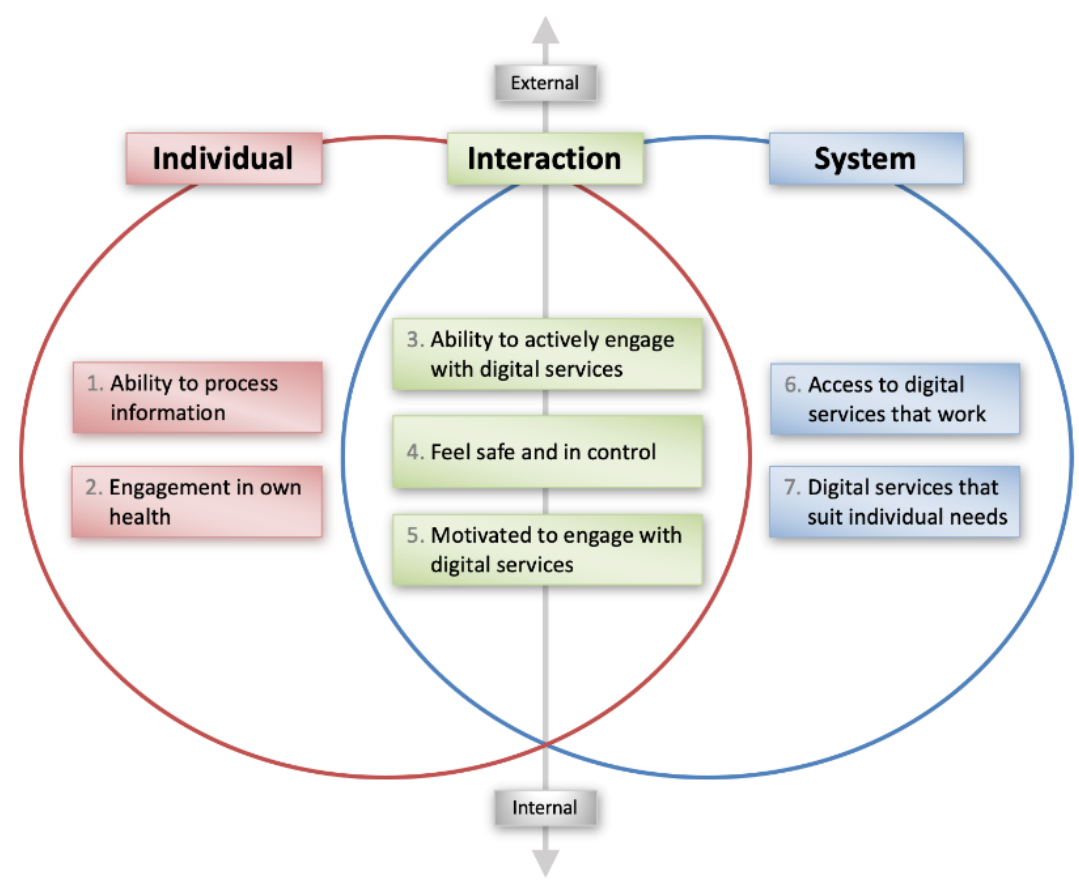

Figure 2: Nørgaard et al. model from 2015, grouping necessary issues and illustrating as necessities for seamless interaction. Permission to reprint the figure is obtained from the rightholders.

Bautista (2015) suggests that quality of life should be considered in the updated definition of eHL: "eHealth literacy involves the interplay of individual and social factors in the use of digital technologies to search, acquire, comprehend, appraise, communicate and apply health information in all contexts of healthcare with the goal of maintaining or improving the quality of life throughout the lifespan."(Bautista, 2015).

Griebel et al.'s (2018) "viewpoint paper" is an interesting contribution to many discussion of eHL. It calls for further updated definitions of eHL, for utilizing standardised measurements tools, for justification of new research by critical appraisal of state of the art, for an approach to eHL that is relevant throughout the lifespan, for considering eHL concerning technology design, constraints or acceptance, and providing guidelines for developers (Griebel et al., 2018).

Two recent contributions to the body of knowledge on eHL can also be mentioned to illustrate the increasing interest in eHL and online health information (OHI). The title of Diviani et al.'s (2019) study of how adults (aged 18-65) relate to $\mathrm{OHI}$ is telling: "Where else should I look for it?" $\mathrm{OHI}$ is always available for individual or groupbased searches and discussions. Magsamen-Conrad et al. (2019) are finding support with the same argument technological and health literacy is a collaborative practice with tech-savvy doers, watchers, teachers, and learners. This collaborative practice enables people to access, analyse, and share OHI. As has been shown above, health literacy is an essential social determinant of health and should not be reduced to an individual risk factor. Interestingly, Papen (2009) suggested more than a decade ago that literacy can be understood as a social practice, as is the Internet. This illustrates a point made by Griebel et al (2018) in their conclusion that existing knowledge often was ignored. It is also worth noting that the practice and research fields of KM and e-health are brought together less frequently than expected.

\subsection{Knowledge management in a health context}

WHO launched their KM strategy in 2005. The mission of WHO Knowledge Management (WHO-KM) is to help bridge the "know-do gap" in global health by fostering an environment that encourages the creation, sharing, and effective application of knowledge to improve health (World Health Organization, 2005).

$\mathrm{KM}$ is a set of principles, tools and practices that enable people to create knowledge and to share, translate and apply what they know to create value and improve effectiveness (World Health Organization, 2005). The WHOKM strategy focuses on national policy-makers, WHO programmes, and health professionals. The objectives of the strategy lie in three main areas - strengthening country health systems through better knowledge 
management, establishing KM in public health, and enabling WHO to become a better learning organisation, through the following strategic directions:

1. Improving access to the world's health information

2. Translating knowledge into policy and action

3. Sharing and reapplying experiential knowledge

4. Leveraging e-Health in countries

5. Fostering an enabling environment

The concept of KM is contested and difficult to pin down. Abell and Oxbrow (2006) offer an example of this when they state that "knowledge management (KM) is like beauty - in the eye of the beholder. There is no universally accepted definition of the term, perhaps reflecting its essential character, its unique interpretation by the organisation that adopts the philosophy" (Abell and Oxbrow, 2006; Maceviciute, 2002). To Maceviciute (2002) this makes the concepts useless. The Girards mapped the terrain in 2015 and demonstrated the depth, breadth, and international nature of KM. According to them, their work is the first attempt to catalog, within the academic literature, KM definitions, especially those with an applied orientation (Girard and Girard, 2015:2).In their KMcatalog, the four most common verbs were: use, create, share, and manage, and the four most common nouns were: knowledge, process, organization, and information. When they considered the words that appear at least 30 times, they offered the following definitions of KM (Girard and Girard, 2015:14):

- $\mathrm{KM}$ is the process of creating, sharing, using and managing the knowledge and information of an organisations.

- $\mathrm{KM}$ is the management process of creating, sharing and using organisational information and knowledge.

For the purpose of this paper, it is interesting to see how KM is defined as a social and collective process of collecting and creating a body of knowledge and a process of using this to connect to peers or organisations (e.g. health services). $\mathrm{KM}$ in health is also related to decision making and decision support, and abilities and willingness to use health technologies, as demonstrated by (WeckHelander and Meristö, 2020).

\section{Methodology and participants}

This study sits in a qualitative sociological tradition (Silverman, 2015). Data is produced through open-ended interviews with 17 participants aged 65-90 years. Eligible participants were home-dwelling adults above 65 years, able to read, hear and communicate in Norwegian without specialized equipment or interpreters. Participants were strategically recruited through snowballing and gatekeepers, e.g. through participants in the previous study (Fredriksen and Sudmann, 2016), research colleagues, health care personnel, neighbours, senior communities, or church services (the city mission and the state church). Participants were recruited from rural and urban municipalities, i.e. small and medium-sized municipalities and large cities. The strategic inclusion of participants allowed us to pay attention to, and secure variation in age, gender, rural/urban place of residence, and education as far as possible, taking into account the extensive changes in the educational system in Norway during the 20th century. Vocational education and training used to be an integrated part of working life in Norway, which makes it difficult to convert previous educational attainments to modern day educational system with basic, secondary, further, higher or post-graduate education (cf. the Bologna process and European higher education).

Participants received printed and e-mailed information from the gatekeepers and received the same information from the researchers after consenting to being contacted. All participants gave oral and written consent to participation and received text messages, e-mails or phone calls before interviews to confirm appointments with the researchers. Recruitment continued until saturation of the material.

Participants from two rural and two urban municipalities in Norway were included (nine men and eight women), see table 1. Educational attainment, converted to current levels of education, are shown in Table 2. All participants had completed continuous education which is not done justice to in table 2 . They used ICT (information and communication technology) from one to three hours a day, on up to seven gadgets (e.g. phone, watch, tablet, laptop, stationary PC, smart TV, gaming console) which were used for different purposes. All participants are Caucasian middle-class Norwegian citizens, as are the researchers. 
Interview venues were optional (e.g. private homes, offices, cafes, activity centres). The interview guide included prompts for $\mathrm{OHI}$ ("How would you go about to find OHI about an athlete's toe or a swollen finger?") to lessen the risks of ethical violations of privacy/personal searches. Some suggested practical demonstrations, others were solicited to demonstrate how they used their preferred device. The interviews lasted 45-90 minutes. They were performed by three of the authors 2017.

Table 1: Participant's age and gender

\begin{tabular}{|l|l|l|l|l|l|l|}
\hline $\begin{array}{l}\text { Age } \\
\text { Gender }\end{array}$ & $65-69$ & $70-74$ & $75-79$ & $80-85$ & $85+$ & No \\
\hline M & 4 & 5 & 0 & 0 & 0 & 9 \\
\hline W & 3 & 0 & 2 & 2 & 1 & 8 \\
\hline
\end{tabular}

Table 2: Participants educational attainments

\begin{tabular}{|l|l|l|l|l|}
\hline $\begin{array}{l}\text { Education } \\
\text { Gender }\end{array}$ & $\begin{array}{l}\text { Basic } \\
1-10 \text { years }\end{array}$ & $\begin{array}{l}\text { Eq. high school } \\
1-3 \text { years }\end{array}$ & $\begin{array}{l}\text { Graduate } \\
1-4 \text { years }\end{array}$ & $\begin{array}{l}\text { Post grad. } \\
\text { 4+ years }\end{array}$ \\
\hline M & 3 & 1 & 3 & 2 \\
\hline W & 3 & 1 & 0 & 4 \\
\hline
\end{tabular}

Interviews were summed up immediately. A written abstract with key points was shared among the researchers the same day, and adjustment or amendment to the interview guide was made immediately, if necessary. Interviews were professionally transcribed and imported into Nvivo11 (Nvivo qualitative data analysis software, 2015). The initial analysis of the material used key concepts in e-HL as analytical tools - i.e. access, appraise and apply $\mathrm{OHI}$. The researchers read the transcripts separately and used eHL-concepts and the analytical strategies and concepts suggested by Silvermann (24) and Alvesson and Kärreman (Alvesson and Kärreman, 2011) to forward and organise the analysis. The latter suggests that the empirical material is viewed as a "mystery", where the analytical process is facilitated by our hunt for paradoxes or breakdowns. It's by de-fragmentation, defamiliarization, problematization, and application of a broad scholarship and reflexive critique we construct and resolve mysteries - i.e. offer interesting answers to our questions and amend the body of knowledge on the subject of interest (Alvesson and Kärreman, 2011).

If new questions are posed to an existing empirical material, here the question of how $\mathrm{KM}$ and eHL relate to seniors use of OHI, Alvesson and Kärreman's (2011) mystery solving approach is a call for an application of a broad scholarship (e.g. KM literature) and reflexive critique.

This paper focuses on the key features of eHL and KM relevant to healthy ageing as presented above: a) individual and socioeconomic factors, b) the different technologies, c) actions taken, d) healthcare context, e) quality of life, and e) lifespan. These features served as an analytical lens for exploring seniors' use of technologies. Therefore, we regrouped and examined a) Knowledge creation and b) Translation and sharing of knowledge c) Applying knowledge. A key challenge for researchers and designers of health technology or online health information, is understanding barriers and drivers for using these resources. The discussion section relates these challenges to definitions of health and $\mathrm{KM}$, and to everyday life as social interaction and participation.

The remaining parts of the paper are organised around eHL as digital practices that relate to accessibility, critical appraisal and application of $\mathrm{OHI}$, and $\mathrm{KM}$ as a set of principles, tools and practices that enable people to create knowledge and to share, translate and apply this knowledge.

The quotes below are translated from Norwegian to English by the first author and sanctioned by the second and third authors. All authors are senior researchers.

\section{Results}

As summarised above, eHL and KM encompasses actions as finding and creating knowledge, accessing, appraising, and applying $\mathrm{OHI}$, using health technologies and digitized services, and eHL and KM implicitly and explicitly put demands on skills, competencies, and socio-materiality (e.g. access to ICT). This section shows how seniors negotiate these demands. 
According to Girard and Girard (2015) the four most common verbs in KM-definitions were use, create, share, and manage, and the four most common nouns were knowledge, process, organization, and information. The nouns and verbs capture knowledge creation processes, translation and sharing and applying online health information.

\subsection{Knowledge creation - finding online health information}

The participants presented themselves from being ignorant to be tech-savvy, depending on the subject matter and the social situation. All participants used computers when they were gainfully employed, e.g. Word Perfect and Excel. All were confident with e-mail, and online services, e.g. online banking, reading news, booking at travel agencies, and social media. All of them owned more than one ICT platform. Even though they were confident in the everyday use of ICT, navigating the Internet for health purposes was a new challenge for them. Later, this will beg questions about how older adults can convert their everyday ICT knowledge to online health behavior and [appreciation of $\mathrm{OHI}$. Keeping up to speed with technology development is harder in retirement, as these quotes illustrate:

"I was among the five first teachers at our school to graduate in computing, almost 40 years ago. It doesn't help me much today because we learned to program (woman, 80)."

"I used to be a leader and computer teacher and taught others how to punch on those old-fashioned computers. Now I'm a computer student because the development in (ICT) is fabulous. I can't keep up, you know (man, 66)."

They were smiling while talking, acknowledging the speed of technological development and their shift from being tech-savvy to lagging behind. Their basic knowledge about ICT made it easy to ask more skilful (often younger) peers, friends, or family for help. All participants expected that their younger family members were able to keep up with technological development better.

"Sometimes I'm able to find it myself, and if not, I ask my daughters or my wife to help me (man, 74)."

They considered e-Literacy to be precarious and to require nurturing e.g. through course work:

"I've been to a course, run by SeniorNet, which was very useful. I've actually been an assistant teacher there as well. SeniorNet has a help-line, and they walk you through everything (woman, 84)."

Where available, the participants showed interest in making themselves familiar with electronic health records (EHR). They all knew that the Internet abounded in health information but were not confident in finding and seeing the differences between diamonds and rhinestones. Few, if any, had any knowledge about how search engines rank search results, and none (save for one) had noticed that the presentation of search hits (e.g. titles, URLs, colors) could be used to evaluate trustworthiness or quality of content. All, except for one guided by an instructor from SeniorNet, took the ranking as a kind of quality assurance (the best at the top) and were annoyed when some of the links were adds.

\subsection{Translating online health information}

All participants launched OHI-searches by entering one or two Norwegian concepts, using the default browser on their preferred device. Searching was motivated by their own concerns or wished to help others, or they were purely curiosities (e.g. regarding celebrities' illnesses):

"I search for $\mathrm{OHI}$ to help others and to get information (man, 74)".

They also searched to get repeat or confirmatory knowledge:

"After I've seen my GP, I go home and search for $\mathrm{OHI}$ to assure myself that I understood the information (woman, 76)."

When a medical diagnosis could identify a complaint, this concept was usually used as a search term:

"When I searched for OHI about my daughter's diagnosis, I just wrote the diagnosis in the search field. I read whatever turns up (man, 74)."

Others did not use the diagnosis as a search term:

"When I search, I describe it, write [about] the symptoms, and then I always get an answer (woman, 88)." 
Searching was motivated by finding information that imparted trustworthiness, coherence, and fidelity (Dahlstrom, 2014; Li et al., 2018). They 'favorited' Norwegian hits and pages without ads. Webdesign and domain owner (health services compared to social media) or author, i.e. from whom the content came, were critically appraised. If the page was "nice" and readable, and the information was recognizable, they were more likely to trust it:

"I've no idea about how I choose or sort information, maybe l've seen it before, or heard of it? ( man, 70)."

Only a few seniors did strategic searches and cross-checked until their queries were settled:

"I google and get an extensive list, which I scroll. You do not open all of them, but look for keywords, and then click the ones that look OK. It must be a serious and really [credible] answer to my queries. The best is when it rings a bell about some previous information so that I can judge the content (woman, 69)."

\subsection{Sharing and applying online health information}

Online health information seeking emerged as a site and case for social participation and interaction (Papen, 2009; Dennis, 2003), which was appreciated, mainly as an opportunity to ponder health concerns :

"Well, sometimes I help others, my peers are my age, and we discuss how we do OHI, and share how and where we find what we need. I see one of my colleagues quite often, we talk about everything, and at our age, ailments and diseases flourish. We share our concerns and our $\mathrm{OHI}$ findings, and we share information (man, 66)."

Online health behaviour and discussions in social media, or with a physically present person, offer an opportunity to consider whether the reason for searching for $\mathrm{OHI}$ should be followed by a GP-visit, or settled by oneself:

"I know that $\mathrm{OHI}$ may contain wrong and misinformation, so if I'm really worried, I always ask those who are knowledgeable. I can ask our daughter, a nurse, to check my medication. Or I go to my GP; our relationship is very good, he would gladly discuss $\mathrm{OHI}$ with me. I don't trust $\mathrm{OHI} 100 \%$, and if I believe something is really serious, I would always see my GP (man, 66)."

Participants reported that different user-interfaces (phone, tablet, laptop computer, desktop computer, health watch, or TV) demanded different skills and presented different challenges. Age takes its toll, and crooked fingers, dry skin, poor eyesight, and small icons or buttons were annoying barriers:

"I have my own PC, but don't use it too much, due to poor eyesight. My tablet is new, and much better for my eyes (woman, 66)."

Age or ability-related barriers were overcome by the changing user-interface, or by collective searches. A striking similarity between the old participants in our study compared to the youngest participants in Diviani et al's study (Diviani et al., 2019), is that OHI is often done in social settings, so search strategies and results can be discussed. The striking differences between these age-groups (comparable to grandchildren and grandparents) is the selfefficacy and confidence the young have in their own ability to find, critically analyse and apply OHI, compared to senior's suspicion of $\mathrm{OHI}$ content, lack of trust in themselves, and reluctance to apply whatever they find:

"I'm very sceptical of $\mathrm{OHI}$, there's too much information. And how can a lay-person sort this information in an intelligible way? (woman, 76)."

"I don't believe this information is doing any good, one gets sicker of it, at the best one is no worse. And not any wiser (man, 70)."

All participants discussed $\mathrm{OHI}$ with family and peers and compared hits on "google" with social media. Many of them were laughingly telling about e-mail commercials, alternative medicine, and Facebook ads, adding a solemn comment like "We are not fooled so easily". They displayed or wished to show a cool attitude (Zimmermann and Grebe, 2014) towards technology and OHI, often with a twinkle. The coolness personified by these seniors can be compared to calmness and self-control. It takes more than an appealing design or userinterface to convince them to act upon online health information.

\section{Discussion}

The discussion section relates these challenges to definitions of eHL and KM, and everyday life as social interaction and participation. 
A key challenge for researchers and designers of health technology or online health information, is understanding barriers and drivers for using these resources. Senior citizens receive and give help on ICT use and online behaviour, whether this is between family members, friends or communities of interest (e.g. the Senior Net or other communities). As shown above, the seniors are rich in the initiative and determined in their quests for information or in their decision to abstain from trusting $\mathrm{OHI}$. If health is to be understood as collective practice, interaction with general practitioners (GPs), is vital for any health resource. This section shows that seniors are quite strategic in their self-presentation and interaction with their GPs (Goffman, 1959; Goffman, 1969). Seniors are considerate to make sure they are welcomed and treated as credible patients (Werner and Malterud, 2003).

The aim of the study was to explore how a select group of Norwegian seniors accessed, appraised and applied online health information $(\mathrm{OHI})$, individually and collectively, and how they evaluated this information compared to face-to-face health-encounters. Our findings do not provide new knowledge about how socio-economic status, or cognitive or physical capabilities affect $\mathrm{OHI}$ behaviour.

Online health information is easily available for everyone. Our participants acknowledge their lacking skills in critical appraisal of OHI's validity and relevance, particularly with their own symptoms or concerns. Discussions with peers and family amend to this, as do their senior coolness (Zimmermann and Grebe, 2014). Health and Internet are social practices for them (Hall et al., 2015; Friemel, 2016; Matthews, Nazroo and Marshall, 2018; Magsamen-Conrad et al., 2019; Nørgaard et al., 2015).

The amount of $\mathrm{OHI}$ is soaring and should be used as a resource for supporting and assuring citizens of all ages to engage in digital services for co-/self-manage of own or others' health. Shared decision-making implies mutual learning to reach WHO e-health goals and to reduce the burden of social inequalities in health due to low ehealth literacy.

The sage advice from this study can be summed up as a cool pragmatic strategy: OHI is relevant for curiosity, easily self-managed minor concerns, and peer support. When you are really worried, and you should see a GP, not use $\mathrm{OHI}$. Their strategy can be supported by including dialogues on $\mathrm{OHI}$ in every health-encounter to promote digital inclusion in later life, particularly inclusion in digital health.

\subsection{Challenges and possibilities in design for collective knowledge management}

Participants were ambivalent towards sharing their online experiences with their GP and health care personnel, as it might affect the outcome of the consultation negatively. The justification for this standpoint was related to the perceived poor quality of $\mathrm{OHI}$ :

"I wouldn't dream of telling my GP about my OHI-searches. I'd rather hear the GP's opinion first, and if I'm unsatisfied or disagree, then I might consult $\mathrm{OHI}$ and try to sort it out afterward. There is so little time to talk, and I want us to stay focused. That's it! No room for discussing the Internet's answers as well (woman, 76)."

Even though few planned to tell their GP about online searches, some expected it would be well received, while others had tried without much of a response:

"I never refer to the Internet, but I think a conversation about it is relevant, and I expect that it would be accepted (man, 74)."

"I don't think the GPs are very happy about us reading on the Internet. When I go there and tell him about what I read on the Internet, he doesn't answer too much (man, 70.)"

A well-known barrier is that one can be led astray - towards more or less depressing results and prognosis of an anticipated disease:

"I'm born into a cancer family, and I believe that's why I'd rather see my GP and get a clear answer, rather than worrying yourself about possible cancer (woman, 69)."

Participants shared with us a variety of health and ICT competencies, interest, knowledge, and skills in OHI, and shared their considerations about when to offer or ask for help and when to see or not see their GPs. All participants discussed a wide range of health issues with family, friends, peers, and researchers, and were not bothered by lacking skills. This supports an understanding of health and Internet as social practices, for reflection 
and learning (Diviani et al., 2019; Hemsley et al., 2018; Huber et al., 2011; Magsamen-Conrad et al., 2019; Nørgaard et al., 2015; Silver, 2015) - at least outside the realm of the health care sector. Citizens' selfpresentation, negotiations and considerations in everyday social interaction emerge as issues designers of ICT and $\mathrm{OHI}$ should consider.

\section{In conclusion}

The aim of the present paper is to present and discuss health KM from senior users of online health information $(\mathrm{OHI})$ point of view. We have explored how they accessed, appraised, and applied OHI individually and collaboratively, and how they evaluated this information compared to face-to-face health-encounters. The paper exemplifies needs to be considered by health care providers for more suitable support for aged citizens. By examining differences in competency in $\mathrm{KM}$ for health and the use of $\mathrm{OHI}$ acquisition and support needed, the results pinpoint how providers must assure aged citizens that $\mathrm{OHI}$ and collective management are assets for healthy aging and managing health concerns.

Our participants acknowledged their lack of trust and/or skills in critical appraisal of the validity and relevance of $\mathrm{OHI}$, particularly about potentially serious health concerns. As shown above, the social settings around internet searches paved the way for discussions with peers and family, which partly compensated for a lack of skills or affirmed their lack of trust in the findings. The coolness they displayed, i.e. being calm and critical towards the content, also made them prioritise seeing their GP when there were any pressing issues or concerns (Zimmermann and Grebe, 2014). Health and Internet are social practices for them (Papen, 2009; Hall et al., 2015; Nørgaard et al., 2015; Friemel, 2016; Matthews, Nazroo and Marshall, 2018; Magsamen-Conrad et al., 2019). This study acknowledges the usefulness of e.g. Wang's suggestion for combining individual and collective access (Wang et al., 2008) to online media to achieve higher trustfulness in the retrieved data.

The seniors in this study used digital technologies daily to access news media, Internet banks, e-mails or travel agencies. They are skilled and active knowledge producers, shares and users. They shifted roles between guiding peers on the Internet and being supervised by peers or younger next of kin - they literally enacted health as a social practice. Interestingly, none of the definitions of eHL presented in section 1, include theoretical discussion or definitions of health. The WHO (1948) definition of health builds on a medically informed approach to the body, which is quite different from Crawford's (2006) understanding of health as a meaningful social practice and Huber'et al.s' (2011) understanding of health as an amalgam of resources (including the body). This might put new definitions of eHL at risk of being less useful and outdated because they do not capture contemporary framings of health as a bodily and social phenomenon. A theoretical discussion of health is necessary when we inquire into the health-related use of digital technologies and the Internet, to understand why and how citizens approach digital health technology at large. Neither of the definitions of eHL discusses citizens' participation in defining or measuring $\mathrm{eHL}$, or their opinions on the usefulness of $\mathrm{OHI}$ in everyday living, quality of life, or in shared decision-making in health-encounters. Lastly, but no less, neither of the framings of eHL acknowledge the complexity of social interaction, ICT use and $\mathrm{OHI}$, and healthy ageing.

The amount of $\mathrm{OHI}$ is soaring and should be used as a resource for supporting and assuring citizens of all ages to engage in digital services for co-/self-management of one's own or others' health. Shared decision-making implies KM and mutual learning to reach WHO e-health goals and to reduce the burden of social inequalities in health due to low e-health literacy. E-health literacy is a social determinant for health, and healthy ageing presupposes e-health literacy - broadly defined. KM - from acquisition to use - is a social practice where the relevance of $\mathrm{ICT}, \mathrm{OHI}$ or knowledge is negotiated in a situated context. Our findings do not provide new knowledge about how socio-economic status or cognitive or physical capabilities affect OHI behaviour. Further studies need to look into this.

Handling eHealth is slowly becoming an integral part of our life, and eHL influences the quality of life (Bautista, 2015; World Health Organization, 2005; World Health Organization, 2016; World Health Organization, 2020). This study illustrated the differences between skills for handling ICT and strategies for interpreting and assessing trustworthiness of $\mathrm{OHI}$ for a group of seniors in Norway. However, further research is needed not primarily for improving user experiences, but on how end-users can be engaged as active participants in design of ICT and $\mathrm{OHI}$ throughout their lifespan, to enhance the value of ICT and $\mathrm{OHI}$ as assets for healthy ageing, quality of life and social participation. 
The current advice from this study can be summed up as a cool pragmatic strategy: $\mathrm{OHI}$ is relevant for curiosity, for easily self-managed minor concerns, and for peer support. However, when really worried, the seniors in this study preferred to see their GP and did not trust OHI. Their strategy can be supported by including dialogues on $\mathrm{OHI}$ in every health encounter to promote digital inclusion in later life, particularly inclusion in digital health. KM related to health is a social practice, and the contingency of ICT or OHI must be addressed.

- $\quad$ E-Health literacy encompasses individual and peer-based knowledge, skills and competencies that are obtained and utilised beyond health care settings.

- Older adults make health-relevant decisions in a wide range of contexts outside the health care sector individually and collectively.

- Health care personnel must acknowledge older adults' online health behaviour, and include their knowledge, skills, and competencies in the dialogues in the consultation room.

- Responses towards emerging aged digital health divides must include alternatives to self-management and digitization and acknowledge older adults as active social learners in digitized or analogue environments.

A first possible step after this study is to examine if the opinions of other older adults in Norway, and maybe as the next step in Scandinavia or other countries are the same concerning their acceptance of health technologies that become a part of their lives. The information may contribute to developing a more adequate methodology to collect data from many. This study begs for an international comparison of how older adults navigate in digitized societies, and if and how digital divides are approached, negotiated and lived.

\section{Acknowledgments}

The authors wish to extend their thanks to the participants in this study, and to the reviewers of the paper. This research project was financed by annual research grants from Western Norway University of Applied Sciences, Bergen, Norway.

\section{References}

Abell, A. and Oxbrow, N. 2006. Competing with knowledge: The information professional in the knowledge management age: London: Facet Publishing.

Alvesson, M. and Kärreman, D. 2011. Qualitative research and theory development. Mystery as method, London: Sage.

Armitage, R. and Nellums, L. B. 2020. Covid-19 and the consequences of isolating the elderly. The Lancet Public Health, 5(5), pp. e256.

Bautista, J. R. 2015. From solving a health problem to achieving quality of life: Redefining ehealth literacy. Journal of Literacy and Technology, 16(2), pp. 33-54.

Bossen, C., Chen, Y. and Pine, K. H. 2019. The emergence of new data work occupations in healthcare: The case of medical scribes. International Journal of Medical Informatics, 123(March), pp. 76-83.

Bowling, A. and Dieppe, P. 2005. What is successful ageing and who should define it? Bmj, 331(7531), pp. $1548-1551$.

Crawford, R. 2006. Health as a meaningful social practice. Health, 10(4), pp. 401-420.

Dahlstrom, M. F. 2014. Using narratives and storytelling to communicate science with nonexpert audiences. Proceedings of the National Academy of Sciences, 111(Supplement 4), pp. 13614-13620.

Dennis, C. L. 2003. Peer support within health care context: A concept analysis. International Journal of Nursing Studies, 40(3), pp. 321-332.

Diviani, N., Fredriksen, E. H., Meppelink, C., Mullan, J., Rich, W. and Sudmann, T. T. 2019. "Where else would i look for it?": An international qualitative study on purposes, strategies, and consequences of online health information seeking. Journal of Public Health Research [Online], 8. Available: https://doi.org/10.4081/jphr.2019.1518.

Fredriksen, E. H. and Sudmann, T. T. 2016. Fra søk til bruk av helseinformasjon på internett: E-health literacy i en norsk kontekst (from search to use of online health information: E-health literacy in a Norwegian context). Fysioterapeuten, 83(10), pp. 26-33.

Friemel, T. N. 2016. The digital divide has grown old: Determinants of a digital divide among seniors. New Media \& Society, 18(2), pp. 313-331.

Gerst-Emerson, K. and Jayawardhana, J. 2015. Loneliness as a public health issue: The impact of loneliness on health care utilization among older adults. American journal of public health, 105(5), pp. 1013-1019.

Gilstad, H. 2014. Toward a comprehensive model of ehealth literacy. In: Jaathun, E. A. A., Brooks, K. E., Berntsen, H. and Gilstad, H. (eds.) Proceedings of the 2nd european workshop on practical aspects of health informatics (pahi 2014). Trondheim, Norway.

Girard, J. and Girard, J. 2015. Defining knowledge management: Toward an applied compendium. Online Journal of Applied Knowledge Management, 3(1), pp. 1-20.

Goffman, E. 1959. The presentation of self in everyday life, London: Penguin.

Goffman, E. 1969. Strategic interaction, Philadelphia: University of Pennsylvania press. 
Goroll, A. H. 2017. Emerging from ehr purgatory-moving from process to outcomes. N Engl J Med, 376(21), pp. 20042006.

Griebel, L., Enwald, H., Gilstad, H., Pohl, A.-L., Moreland, J. and Sedlmayr, M. 2018. Ehealth literacy research-quo vadis? Informatics for Health and Social Care, 43(4), pp. 427-442.

Hall, A. K., Bernhardt, J. M., Dodd, V. and Vollrath, M. W. 2015. The digital health divide: Evaluating online health information access and use among older adults. Health Education \& Behavior, 42(2), pp. 202-209.

Hemsley, B., Rollo, M., Georgiou, A., Balandin, S. and Hill, S. 2018. The health literacy demands of electronic personal health records (e-phrs): An integrative review to inform future inclusive research. Patient education and counseling, 101(1), pp. 2-15.

Huber, M., Knottnerus, J. A., Green, L., van der Horst, H., Jadad, A. R., Kromhout, D., Leonard, B., Lorig, K., Loureiro, M. I. and van der Meer, J. W. 2011. How should we define health? BMJ 10.1136/bmj.d4163.

Kickbusch, I. S. 2001. Health literacy: Addressing the health and education divide. Health promotion international, 16(3), pp. 289-297.

Levesque, J.-F., Harris, M. F. and Russell, G. 2013a. Patient-centred access to health care: Conceptualising access at the interface of health systems and populations. International journal for equity in health, 12(1), pp. 18.

Levesque, J.-F., Harris, M. F. and Russell, G. 2013b. Patient-centred access to health care: Conceptualising access at the interface of health systems and populations. International Journal for Equity in Health, 12(1), pp. article 18.

Li, J., Tang, J., Liu, X. and Ma, L. 2018. How do users adopt health information from social media? The narrative paradigm perspective. Health Information Management Journal, 48(3), pp. 116-126.

Maceviciute, E. 2002. Review of Abell, Angela and Oxbrow, Nigel: Competing with knowledge: The information professional in the knowledge management age. Information Reseach, 8(1), pp. Review no. R070.

Magsamen-Conrad, K., Dillon, J. M., Billotte Verhoff, C. andFaulkner, S. L. 2019. Online health-information seeking among older populations: Family influences and the role of the medical professional. Health Communication, 34(8), pp. 859871.

Matthews, K., Nazroo, J. and Marshall, A. 2019. Digital inclusion in later life: Cohort changes in internet use over a ten-year period in england. Ageing \& Society, 39(9), pp. 1914-1932.

Niehaves, B. and Plattfaut, R. 2014. Internet adoption by the elderly: Employing is technology acceptance theories for understanding the age-related digital divide. European Journal of Information Systems, 23(6), pp. 708-726.

Nishijima, M., Ivanauskas, T. M. and Sarti, F. M. 2017. Evolution and determinants of digital divide in brazil (2005-2013). Telecommunications Policy, 41(1), pp. 12-24.

Nørgaard, O., Furstrand, D., Klokker, L., Karnoe, A., Batterham, R., Kayser, L. and Osborne, R. H. 2015. The e-health literacy framework: A conceptual framework for characterizing e-health users and their interaction with e-health systems. Knowledge Management \& E-Learning: An International Journal (KM\&EL), 7(4), pp. 522-540.

Nutbeam, D. 2008. The evolving concept of health literacy. Social Science \& Medicine, 67(12), pp. 2072-2078.

Nvivo qualitative data analysis software. 2015. 11 ed.Melbourne: QSR International Pty Ltd.

Papen, U. 2009. Literacy, learning and health-a social practices view of health literacy. Literacy and Numeracy Studies: An InternationalJjournal in the Education and Training of Adults, 16(2-1), pp. 19-34.

Rhoades, H., Wenzel, S. L., Rice, E., Winetrobe, H. and Henwood, B. 2017. No digital divide? Technology use among homeless adults. Journal of Social Distress and the Homeless, 26(1), pp. 73-77.

Rowe, J. W. and Kahn, R. L. 1997. Successful aging. The gerontologist, 37(4), pp. 433-440.

Rowe, J. W. and Kahn, R. L. 2015. Successful aging 2.0: Conceptual expansions for the 21st century. The Journals of Gerontology: Series B, 70(4), pp. 593-596.

Silver, M. P. 2015. Patient perspectives on online health information and communication with doctors: A qualitative study of patients 50 years old and over. Journal of Medical Internet Research, 17(1), pp. e19.

Silverman, D. 2015. Interpreting qualitative data, 5th, London, UK: Sage.

Stephens, C. 2017. From success to capability for healthy ageing: Shifting the lens to include all older people. Critical Public Health, 27(4), pp. 490-498.

Tennant, B., Stellefson, M., Dodd, V., Chaney, B., Chaney, D., Paige, S. andand Alber, J. 2015. Ehealth literacy and web 2.0 health information seeking behaviors among baby boomers and older adults. Journal of Medical Internet Research, 17(3), pp. e70.

Van Deursen, A. J. and Helsper, E. J. 2015. A nuanced understanding of internet use and non-use among the elderly. European journal of communication, 30(2), pp. 171-187.

Wagner, N., Hassanein, K. and Head, M. 2010. Computer use by older adults: A multi-disciplinary review. Computers in human behavior, 26(5), pp. 870-882.

Wang, Z., Walther, J. B., Pingree, S. and Hawkins, R. P. 2008. Health information, credibility, homophily, and influence via the internet: Web sites versus discussion groups. Health communication, 23(4), pp. 358-368.

Weck, M., Helander, N. and Meristö, T. 2020. Active digiage-technology acceptance by ageing people. International Journal of Telemedicine and Clinical Practices, 3(3), pp. 223-242.

Werner, A. and Malterud, K. 2003. It is hard work behaving as a credible patient: Encounters between women with chronic pain and their doctors. Social Science \& Medicine, 57(8), pp. 1409-1419.

Wiles, J. L., Leibing, A., Guberman, N., Reeve, J. and Allen, R. E. 2011. The meaning of "ageing in place" to older people. The gerontologist, 52(3), pp. 357-366. 
Wiljer, D., Urowitz, S., Apatu, E., DeLenardo, C., Eysenbach, G., Harth, T., Pai, H. and Leonard, K. 2008. Patient accessible electronic health records: Exploring recommendations for successful implementation strategies. Journal of Medical Internet Research, 10(4), pp. e34.

World Health Organization 2016. Global diffusion of ehealth: Making universal health coverage achievable. Report of the third global survey on ehealth, Licence: CC BY-NC-SA 3.0 IGO., Geneva, Switzerland: WHO.

World Health Organization 2017a. Global diffusion of ehealth: Making universal health coverage achievable: Report of the third global survey on ehealth. Geneva, Switzerland: WHO.

World Health Organization. 1948. Who definition of health. Geneva, Switzerland: WHO.

World Health Organization. 2005. Knowledge management strategy. WHO/EIP/KMS/2005.1. Geneva, Switzerland: WHO.

World Health Organization. 2017b. The global strategy and action plan on ageing and health. Geneva, Switzerland: WHO. ().

World Health Organization. 2020. E-health [Online]. Geneva, Switzerland: WHO. Available at: https://www.who.int/ehealth/en/ [Accessed 25 March 2020].

Zimmermann, H.-P. and Grebe, H. 2014. "Senior coolness": Living well as an attitude in later life. Journal of Aging Studies, 28(January), pp. 22-34.

Zurita, L. and Nøhr, C. 2004. Patient opinion - EHR assessment from the users perspective. Medinfo, 107(Pt2), pp. 13331336. 